\title{
On the Link between Summer Dry Bias over the U.S. Great Plains and Seasonal Temperature Prediction Skill in a Dynamical Forecast System ${ }^{0}$
}

\author{
Constantin Ardilouze, lauriane Batté, Bertrand Decharme, and Michel Déqué \\ CNRM, Université de Toulouse, Météo France, CNRS, Toulouse, France
}

(Manuscript received 4 February 2019, in final form 14 June 2019)

\begin{abstract}
Soil moisture anomalies are expected to be a driver of summer predictability for the U.S. Great Plains since this region is prone to intense and year-to-year varying water and energy exchange between the land and the atmosphere. However, dynamical seasonal forecast systems struggle to deliver skillful summer temperature forecasts over that region, otherwise subject to a consistent warm-season dry bias in many climate models. This study proposes two techniques to mitigate the impact of this precipitation deficit on the modeled soil water content in a forecast system based on the CNRM-CM6-1 model. Both techniques lead to increased evapotranspiration during summer and reduced temperature and precipitation bias. However, only the technique based on a correction of the precipitation feeding the land surface throughout the forecast integration enables skillful summer prediction. Although this result cannot be generalized for other parts of the globe, it confirms the link between bias and skill over the U.S. Great Plains and pleads for continued efforts of the modeling community to tackle the summer bias affecting that region.
\end{abstract}

\section{Introduction}

In a context of global warming, the occurrence of extreme summer heat at midlatitudes is expected to increase throughout the twenty-first century (e.g., Schoetter et al. 2015). Considering the multiple socioeconomic impacts of anomalously warm temperatures, such as heat-related diseases, crop failure, or energy shortages, improving summer predictions a few months in advance is highly relevant to foster preparedness (Hewitt et al. 2013).

However, state-of-the-art dynamical forecast systems exhibit limited skill in predicting boreal summer temperature over midlatitudes. El Niño-Southern Oscillation (ENSO) is a predominant driver of predictability at the seasonal scale, but the atmospheric teleconnections prone to remotely convey the tropical signal toward midlatitudes are weak in summer (Brönnimann 2007). Thus, taking into account local sources of predictability stemming from the land surface state is crucial to hope

Supplemental information related to this paper is available at the Journals Online website: https://doi.org/10.1175/WAF-D-190023.s1.

Corresponding author: Constantin Ardilouze, constantin.ardilouze@ meteo.fr for skillful warm season forecasts. A number of empirical studies have established a relationship between spring soil moisture and subsequent summer heat over many regions, including large parts of Europe, North and South America, and Australia (Quesada et al. 2012; Mueller and Seneviratne 2012). The contribution of soil moisture to seasonal climate predictability is only relevant in those regions where the two legs of land-atmosphere coupling apply. The terrestrial leg corresponds to the dependence of the evaporative fraction to soil moisture content (Dirmeyer 2011), and the atmospheric leg implies a sensitivity of the surface climate to surface fluxes via boundary layer processes (Santanello et al. 2011). Over these hotspots of landatmosphere coupling, soil moisture initialization in coupled prediction systems is expected to improve the temperature and precipitation forecast skill. Several studies have partly confirmed this hypothesis for temperature (Koster et al. 2011; Prodhomme et al. 2016; Infanti and Kirtman 2016) and precipitation (Kim and Wang 2007). More recently, based on a multisystem approach, Ardilouze et al. (2017) found that soil moisture initialization failed to increase summer prediction skill over the U.S. Great Plains, otherwise identified as a major hotspot of land-atmosphere coupling (e.g., Koster et al. 2004). The study pinpointed the warm and dry summer biases affecting that region 
TABLE 1. CNRM-CM6-1 GCM initialization and resolution.

\begin{tabular}{lllcc}
\hline \hline \multicolumn{1}{c}{ Component } & \multicolumn{1}{c}{ Name } & \multicolumn{1}{c}{ Initialization } & $\begin{array}{c}\text { Horizontal } \\
\text { resolution }\end{array}$ & Vertical levels \\
\hline Atmosphere & ARPEGE-CLIMAT & ERA-Interim & Tl127 $(\sim 150 \mathrm{~km})$ & 91 \\
Land surface & ISBA & SURFEX offline simulation & Tl127 $(\sim 150 \mathrm{~km})$ & Soil: 14, snow: 12 \\
River streamflow & CTRIP & SURFEX offline simulation & $50 \mathrm{~km}$ & - \\
Ocean & NEMO & Mercator-Ocean & $1^{\circ}$ & 75 \\
Sea ice & GELATO & Mercator-Ocean & $1^{\circ}$ & 9 \\
\hline
\end{tabular}

in the five contributing forecast systems as a potential culprit for this lack of skill. These biases are indeed shared by a majority of climate models (e.g., Lin et al. 2017; Zhang et al. 2018). Consequently, whatever the initial soil moisture anomaly, the lack of precipitation and excessive temperatures lead to a spuriously fast drying out of the soil at early stages of the model integration. This could thereby ruin the soil moisture interannual variability brought by land surface initial conditions and consequently reduce the predictive capacity of dynamical forecast systems over the U.S. Great Plains. The present study addresses this hypothesis by comparing two methods designed to preserve the soil moisture imprint on the overlying atmosphere in a forecast system, and assessing their impact on summer temperature forecast skill. These methods consist of scaling either the soil water content in the initial conditions or the precipitation rate captured by the land surface throughout the forecast integration. Section 2 describes these methods as well as the characteristics of the model and the datasets used as references in our evaluations. Results on climate biases, ensemble spread, and forecast skill are presented in section 3. The final section discusses these results and suggests a way forward.

\section{Method and reference data}

\section{a. Model and reforecast setup}

The three experiments consist in 30-member ensemble reforecasts carried out with the CNRM-CM6-1 general circulation model (Voldoire et al. 2019). These reforecasts rely on initialized 4-month model integrations (May-August) run each year of the 1993-2014 period. The 30 -member ensemble is generated by initializing clusters of 10 members on three successive days, namely, 29 and 30 April and 1 May. Within each cluster, randomly drawn initial perturbations are added to the atmospheric initial conditions so as to trigger ensemble spread. The atmosphere is initialized with ERA-Interim (Dee et al. 2011). ERA-Interim with corrected precipitation (Decharme and Douville 2006; Szczypta et al. 2011) is used to provide forcing conditions to an offline integration of the surface modeling platform Surface Externalisée (SURFEX). This surface module embeds the land component ISBACTRIP (Decharme et al. 2019) from which land and river initial conditions are derived. Finally, the ocean and sea ice components are initialized with dedicated Mercator-Ocean products derived from the Global Ocean Reanalysis and Simulation (GLORYS) reanalysis (Ferry et al. 2010). The initial conditions and resolutions for all the components are listed in Table 1. We call CTRL the control experiment following this very setup. The other two experiments only differ from CTRL by the application of either a precipitation correction at each time step (hereafter PERT) or a soil moisture correction in the land surface initial conditions (hereafter INIT). The details of the experimental design for PERT and INIT experiments are provided below.

\section{b. Description of the perturbed experiments}

\section{1) PERT: IN-RUN PRECIPITATION CORRECTION}

As stated in the introduction, the method is based on the correction of the precipitation rate feeding the land surface component of the dynamical forecast system during the course of the forecast integration. The spatially varying corrective factor aims at compensating on average the precipitation bias, so as to keep soil moisture unaffected by this bias. The correction consists in multiplying the precipitation rate reaching the land surface at each time step of PERT, by a given factor. This factor remains constant during a given calendar month of the model integration and is derived from the precipitation bias of that particular month, previously estimated after the CTRL simulation. Therefore, the method is two-stepped. First, the monthly precipitation relative bias of CTRL is computed against a reference dataset OBS at each grid cell of the model (Fig. 2a). In the second step, the PERT reforecast is performed, similarly to CTRL but with the land-precipitation correction applied at each time step (Fig. 1b). The monthly precipitation relative bias of the CTRL experiment is computed over continents against Multi-Source Weighted-Ensemble 

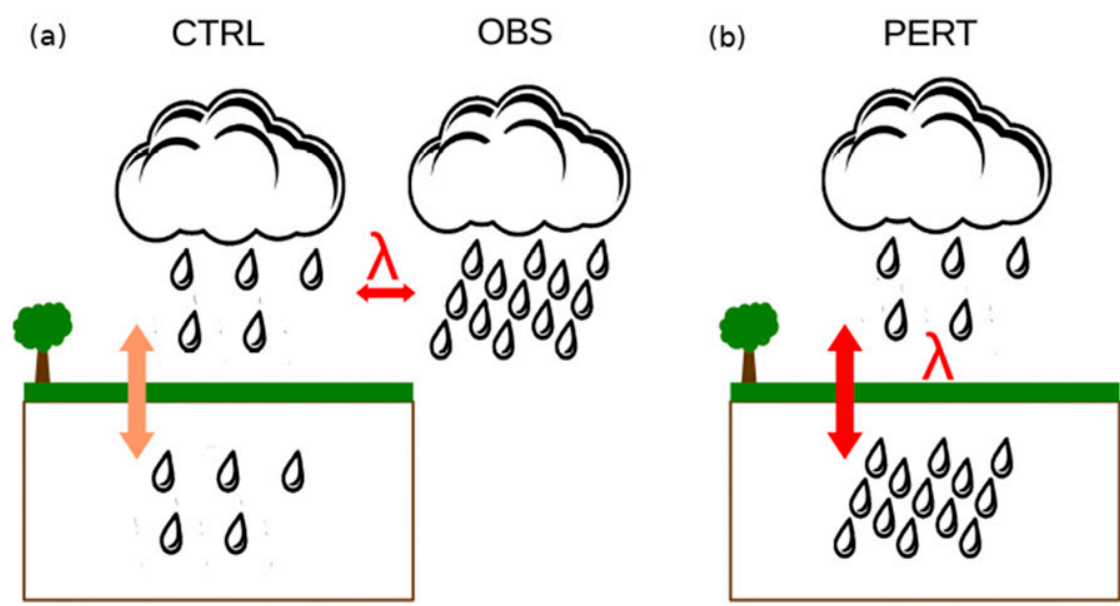

FIG. 1. (a) Monthly precipitation bias $\lambda$ is computed after a CTRL simulation against a reference dataset OBS and (b) is used to multiply the precipitation feeding the land surface at each time step of PERT simulation. The expected change in the land-atmosphere feedback is schematized by the bolder color of the double-headed arrow in (b).

Precipitation (MSWEP) v1.2 (Beck et al. 2017) following Eq. (1), where $P$ is the precipitation rate, $i$ and $j$ the latitude and longitude gridcell coordinates, and $m$ the considered month. The overline indicates a monthly averaged value. This results in a two-dimensional set of values $\lambda(i, j)$ for each of the four months MayAugust:

$$
\lambda(i, j, m)=\frac{\sum_{1993}^{2014} \overline{P_{m}^{\mathrm{OBS}}(i, j)}}{\sum_{1993}^{2014} \overline{P_{m}^{\mathrm{CTRL}}(i, j)}} .
$$

While performing the PERT simulation, the precipitation rate feeding the land surface $P_{\text {Land }}$ is computed at each model time step of month $m$ as in Eq. (2), where $P$ is the precipitation rate simulated by the atmospheric component of the model:

$$
P_{\text {Land }}(i, j, m)=\lambda(i, j, m) P(i, j, m) .
$$

\section{2) INIT: CORRECTION OF SOIL MOISTURE IN THE LAND SURFACE INITIAL CONDITIONS}

The root-zone soil water content in CTRL land surface initial conditions is lower than in the ERAInterim/Land (hereafter ERA-Land; Balsamo et al. 2015) and Global Land Evaporation Amsterdam Model (GLEAM) v3.1a (Miralles et al. 2011; Martens et al. 2017) reconstructions at the same date over the central United States (Fig. S1 in the online supplemental material). These reconstructions, together with CTRL initial conditions, are derived from land surface models, and we cannot ascertain which of them provides the best estimate of the true soil moisture state. However, if land surface initial conditions are effectively too dry, the seasonal impact of soil moisture anomalies on the atmosphere may be underestimated. The INIT experiment aims at verifying this hypothesis. The land surface initial conditions of INIT are similar to CTRL except for the soil water content in each soil layer, which is multiplied by a corrective factor. This factor $\mu(i, j)$ is computed for each soil layer $l$, following Eq. (3) where $\mathrm{WG}_{l}$ is the soil water content in layer $l$ on 1 May:

$$
\mu(i, j, l)=\frac{\sum_{1993}^{2010} \mathrm{WG}_{l}^{\text {ERALand }}(i, j)}{\sum_{1993}^{2010} \mathrm{WG}_{l}^{\mathrm{CTRL}}(i, j)} .
$$

The mismatch between ERA-Land and CTRL soil discretization and horizontal resolution is solved by means of the transfer function implemented by Boisserie et al. (2016). Moreover, ERA-Land reanalysis does not cover years beyond 2010, hence the 1993-2010 period used in Eq. (3). Finally, INIT land initial conditions are obtained from CTRL initial conditions as in Eq. (4):

$$
\mathrm{WG}^{\mathrm{INIT}}(i, j, l)=\mu(i, j, l) \mathrm{WG}^{\mathrm{CTRL}}(i, j, l) .
$$

\section{c. Reference dataset for verification and region of interest}

Although both INIT and CTRL methods are applied and assessed at the global scale, the target region 
(a)

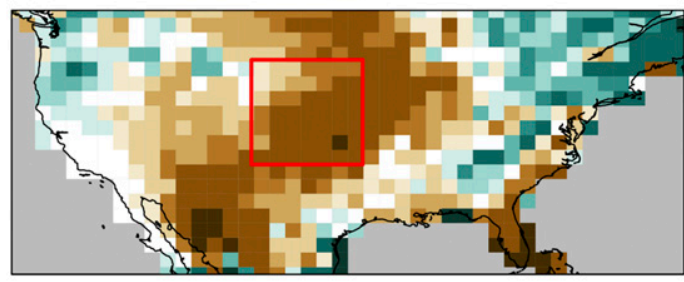

(b)

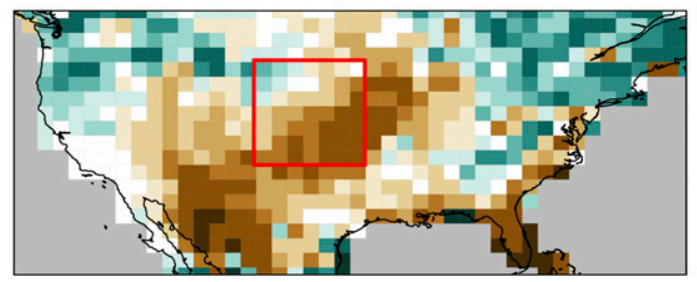

(c)

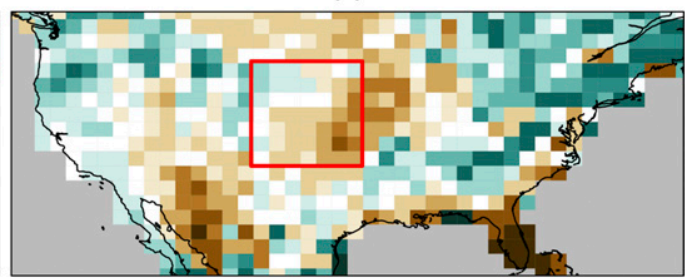

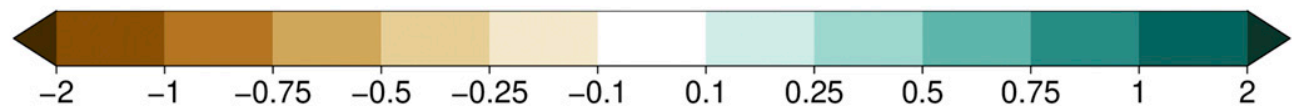

FIG. 2. JJA precipitation bias against GPCC over the United States (mm day ${ }^{-1}$ ) for (a) CTRL, (b) INIT, and (c) PERT. The red box outlines the boundaries of the SGP region.

of this study is the U.S. Southern Great Plains (SGP). The boundaries of this region are unchanged with respect to Ardilouze et al. (2017) $\left(105^{\circ}-95^{\circ} \mathrm{W}, 35^{\circ}-45^{\circ} \mathrm{N}\right)$. Bias and prediction skill are computed against the GPCC v7 dataset (Schneider et al. 2017, 2018) for precipitation and CRU TS4.01 (Harris et al. 2014; Harris and Jones 2017) for 2-m temperature (T2M hereafter). Because of scarce root-zone soil moisture observations, global gridded reference datasets are based on reconstructed soil moisture fields derived from land surface models. Here, three different products have been used to account for the large observational uncertainty: the offline ISBA-CTRIP simulation used to initialize the land surface in our experiments (cf. section 2a), GLEAM, and ERALand.

(a)

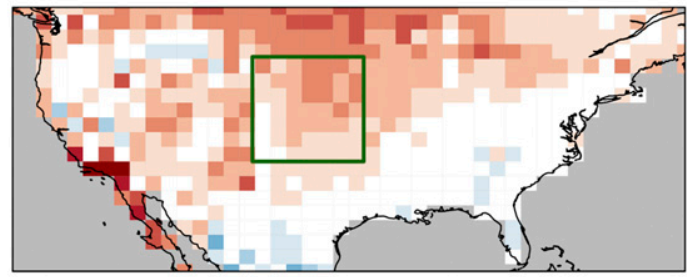

(b)

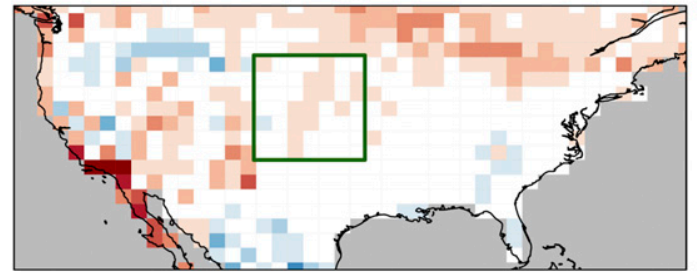

(c)

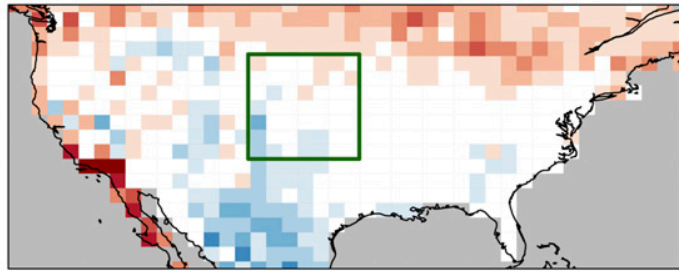

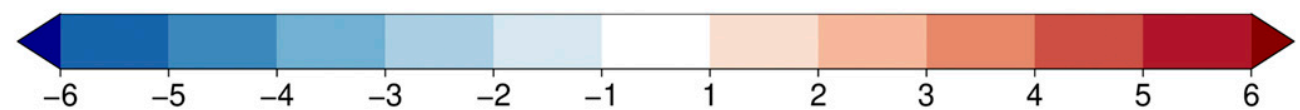

FIG. 3. JJA 2-m temperature bias against CRU TS4 over the United States (K) for (a) CTRL, (b) INIT, and (c) PERT. The green box outlines the boundaries of the SGP region. 
TABLE 2. SGP summer bias against GPCC for precipitation $\left(\mathrm{mm} \mathrm{day}^{-1}\right)$ and CRU TS4 for 2-m temperature (K).

\begin{tabular}{lcc}
\hline \hline Experiment & Precipitation & Temperature \\
\hline CTRL & -1.14 & 2.22 \\
INIT & -0.64 & 0.60 \\
PERT & -0.28 & -0.36 \\
\hline
\end{tabular}

\section{Results}

\section{a. Surface climate bias}

By modifying the soil water content, the techniques described in $2 b$ indirectly impact the rate of bare soil evaporation and vegetation transpiration, and therefore the surface temperature and precipitation. Figures 2 and 3 show the mean precipitation and T2M seasonal bias over a section of North America. The corresponding values over SGP are reported in Table 2. Consistently with many climate models, CTRL is concerned by a large dry and warm bias. Results for PERT and INIT show that both methods are able to mitigate summer temperature and precipitation biases over the target region, although more efficiently with PERT. More generally, INIT and PERT rarely reverse the sign of the precipitation bias, but clearly reduce negative patterns. For T2M, it is noticeable that the bias turns slightly negative in PERT, which can be related to an excessive evapotranspiration (Fig. 4c) although the reference data for evapotranspiration are derived from land surface modeling and thus somewhat uncertain. The method applied in INIT only concerns initial conditions while that used for PERT applies throughout the whole model integration. Hence, we expect differences in the temporal evolution of biases. The mean May-August evolution of precipitation, T2M, and evapotranspiration is illustrated in Figs. 5a-c, respectively. Figure 5d displays an attempt to compare the evolution of the mean root-zone soil moisture on the SGP region between the three experiments. Due to the lack of observational data, global gridded reference datasets for the root-zone soil moisture are derived from land surface model outputs and therefore quite uncertain. Here, we use three distinct datasets as references to take this uncertainty into account, namely, ERA-Land, GLEAM, and ISBA-CTRIP. Interestingly, the May T2M bias is suppressed in INIT, with respect to PERT and CTRL, but at the expense of excessive precipitation and evapotranspiration. CTRL and INIT exhibit similar evolutions for the four fields as shown by nearly parallel curves, thereby showing that the adjustment of soil moisture initial conditions in INIT does not counterbalance the processes involved in the bias growth. In PERT, the temporal evolution of precipitation and evapotranspiration better matches the observation but at the expense of an excessively cool T2M in August. On the other hand, soil moisture increases throughout summer, unlike the reference data and the other experiments. By design, the correction method applied in PERT keeps boosting the precipitation rate, feeding the land surface in these regions throughout the whole summer. Thus, while the precipitation rate produced by the atmosphere gets

(a)

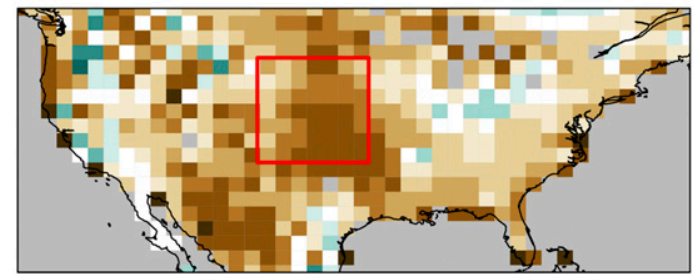

(b)

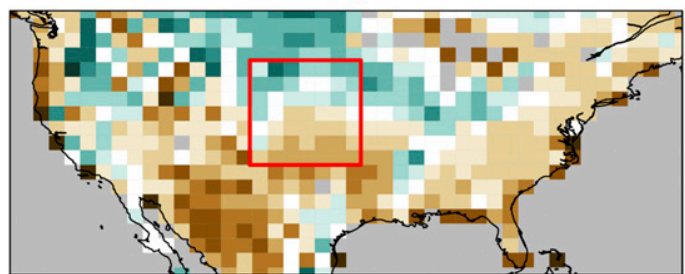

(c)

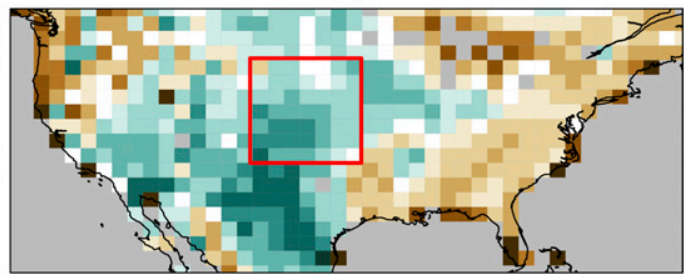

0.
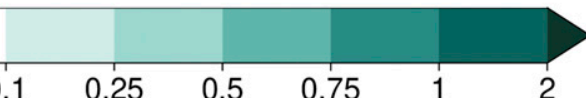

FIG. 4. JJA evapotranspiration bias against GLEAM over the United States (mm day ${ }^{-1}$ ) for (a) CTRL, (b) INIT, and (c) PERT. The red box outlines the boundaries of the SGP region. 


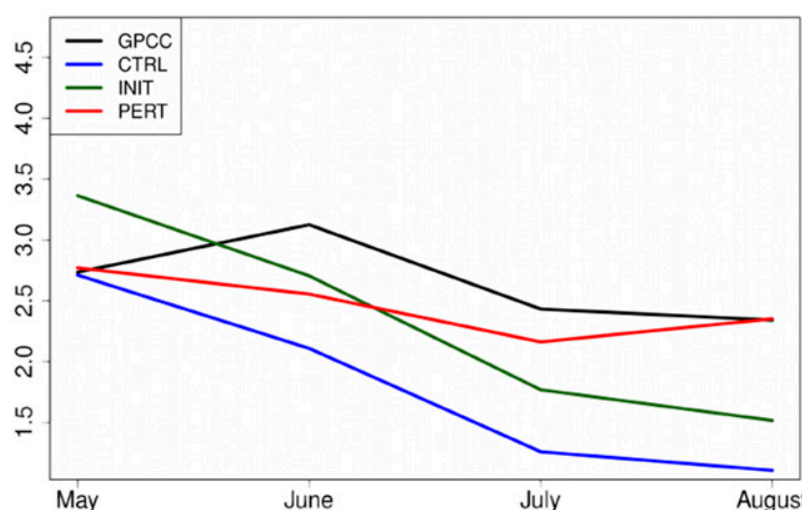

(a)

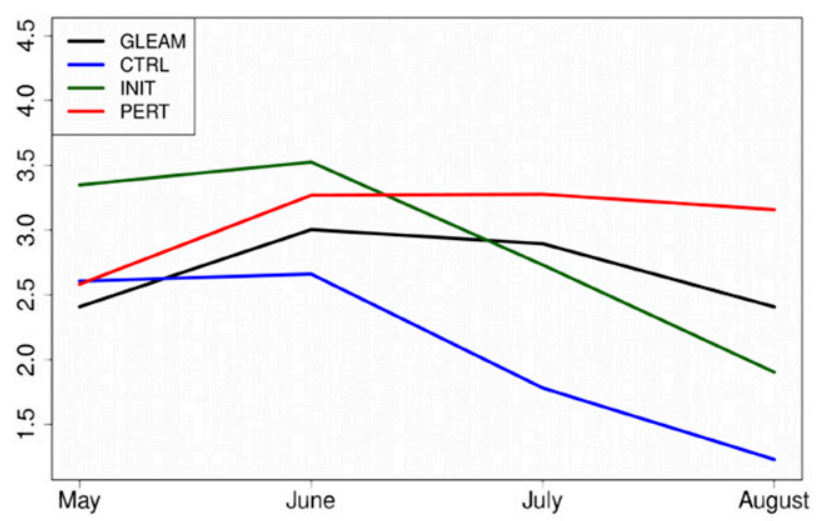

(c)

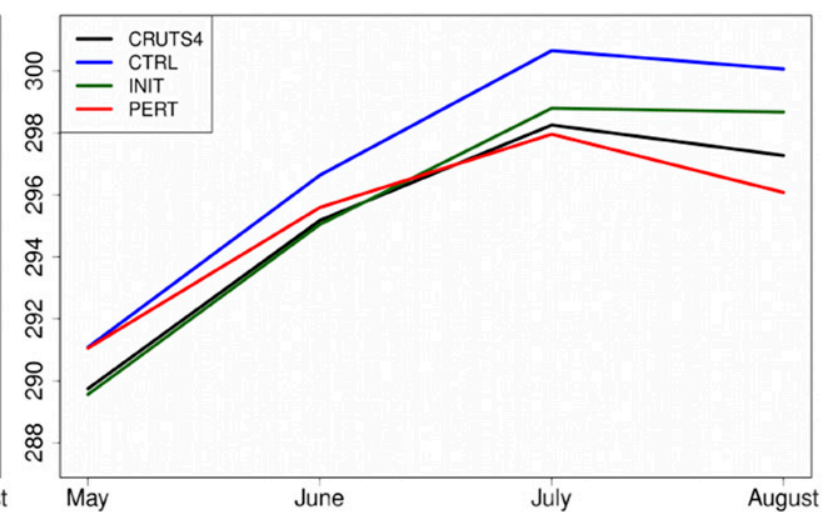

(b)

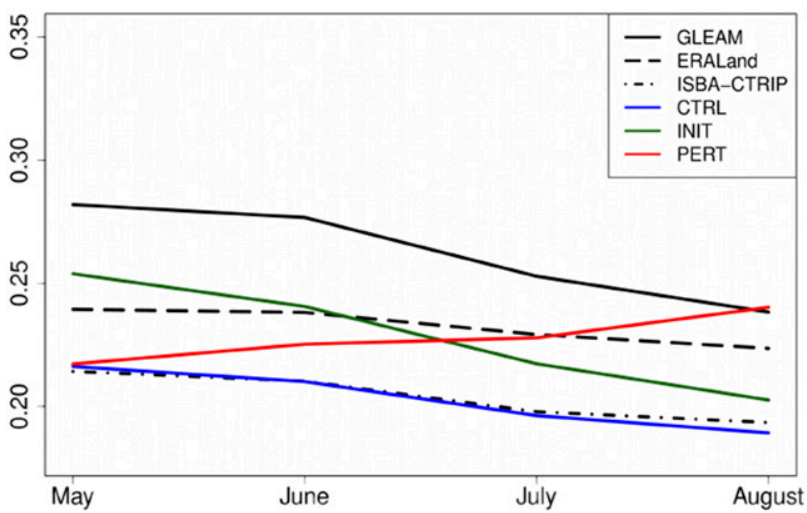

(d)

FIG. 5. May-August monthly mean (a) precipitation $\left(\mathrm{mm} \mathrm{day}^{-1}\right)$, (b) 2-m temperature (K), (c) evapotranspiration $\left(\mathrm{mm} \mathrm{day}^{-1}\right)$, and (d) root-zone water content $\left(\mathrm{m}^{3} \mathrm{~m}^{-3}\right)$ over the SGP region. For CTRL, INIT, and PERT, monthly mean values correspond to the ensemble mean.

progressively closer to observations, via enhanced evapotranspiration and rainfall, the amount of precipitated water seeping the land surface keeps increasing. Overall, the PERT experimental design succeeds in mitigating the bias growth throughout summer. Nevertheless, these results also highlight that temperature and precipitation biases are not linearly dependent, which suggests that other processes than the landatmosphere feedback are at play in the summer bias growth over the SGP region.

\section{b. Ensemble spread}

Beyond the impact on the mean state, the ensemble setup allows us to study how the methods affect the model interannual and intra-ensemble variabilities. Figure 6 compares the root-zone soil moisture ensemble spread for each year of the reforecast period. Regardless of the bias discussed earlier, the CTRL simulation systematically displays a small intra-ensemble spread. On the other hand, the spread is very much increased in PERT, but also INIT to a lesser extent. With all due caution regarding the use of any soil moisture reference dataset, it is worth noting that the PERT root-zone water content interquartile spread better compares to GLEAM than the other experiments. The intra-ensemble variance for evapotranspiration, precipitation and $\mathrm{T} 2 \mathrm{M}$ is also significantly increased in PERT with respect to CTRL, as reported in Table 3. This result demonstrates that the temperature and precipitation summer biases in the model are associated to a limited variability of soil moisture which also affects all the chain of interactions with the atmosphere. The change of soil moisture in PERT therefore contributes not only to correct mean biases, but also to unlock the intra-ensemble surface climate variability. This characteristic is promising but does not give insight on the forecast skill, which is assessed in the following section. As a preliminary analysis, we evaluate the interannual variability of the ensemble mean for soil moisture, which is increased in PERT 


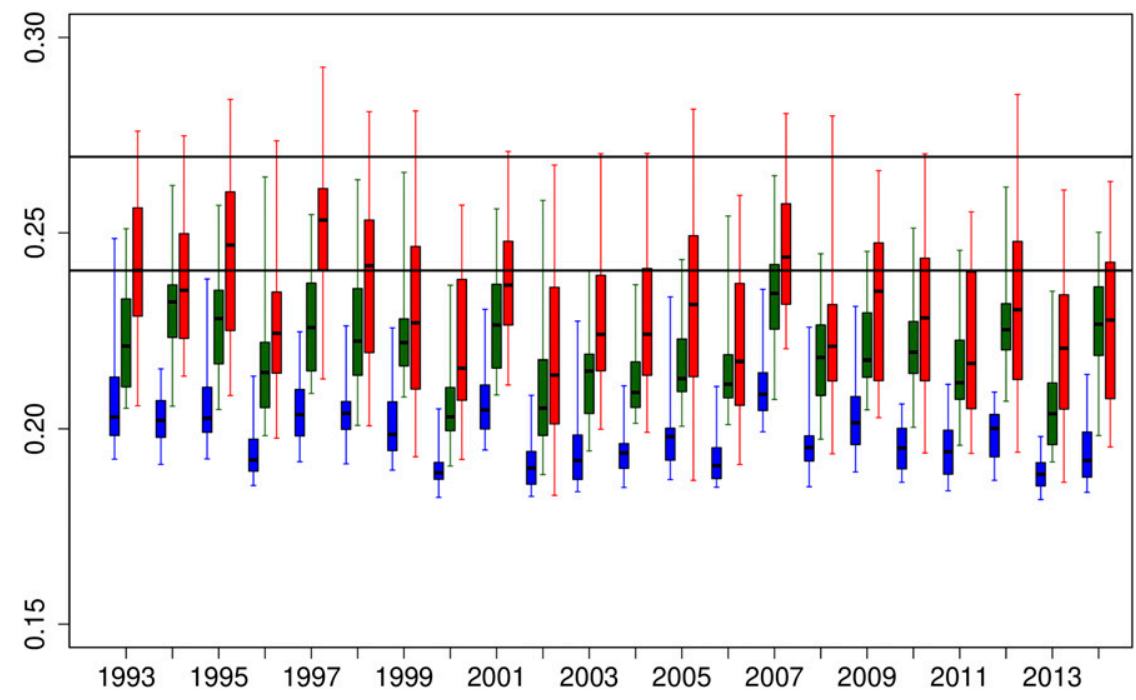

FIG. 6. Yearly summer root-zone water content ensemble distribution $\left(\mathrm{m}^{3} \mathrm{~m}^{-3}\right)$ over the SGP region for CTRL (blue), INIT (green), and PERT (red). The boxes display the interquartile range, and the whiskers extend until the extreme distribution values. The black horizontal lines represent the 25th and 75th percentile of the 1993-2014 GLEAM summer root-zone water content distribution.

(standard deviation of $9.1 \times 10^{-3} \mathrm{~m}^{3} \mathrm{~m}^{-3}$ ) with respect to $\operatorname{CTRL}\left(6.4 \times 10^{-3} \mathrm{~m}^{3} \mathrm{~m}^{-3}\right)$, although not significantly according to the Fisher-Snedecor test on variances. However, neither PERT nor INIT seems to modify consequently the interannual variability of evapotranspiration, temperature and precipitation.

\section{c. Forecast skill}

One aspect of the skill of a temperature seasonal forecast is its ability to capture the correct sign of temperature anomalies over a given reforecast period, which can be assessed through temporal correlation. However, due to a warming climate over the 1993-2014 reforecast period, warm anomalies tend to be overrepresented at the end of the period. Thus, the skill of a reforecast may be overstated if the correlation merely reflects this warming trend. Here, correlations are computed after removing a linear trend in the observed and simulated time series. Detrended correlations between simulated and observed summer temperature at the gridcell scale are compared for the three simulations in Figs. 7a-c. CTRL and INIT broadly show similar positive correlation patterns over western and southeastern United States, but no skill over SGP. The correlation difference (Fig. 7d) is small over SGP and not significant elsewhere, according the Steiger test (Steiger 1980). On the other hand, PERT reforecast is skillful over a portion of the SGP region, and the pattern of correlation increase (Fig. 7e) partly matches that of precipitation bias reduction (Fig. 2). This improved correlation is confirmed in Fig. 8 and cannot be attributed to one single sign (i.e., positive or negative) of anomalies. PERT better captures the anomaly sign in the years corresponding to the extrema of the time series of observed anomalies, namely, 2004 and 2012, but the short length of the reforecast period does not allow further speculation on a the predictability of extreme years. Concerning precipitation, no skill is found with the three experiments (not shown). This result for precipitation was expected, considering that the SGP summer precipitation mainly results from mesoscale convective systems poorly simulated by

TABLE 3. The 1993-2014 average of intra-ensemble variance for SGP summer root-zone water content $\left(\mathrm{m}^{6} \mathrm{~m}^{-6}\right)$, evapotranspiration $\left(\mathrm{mm}^{2} \mathrm{day}^{-2}\right)$, precipitation $\left(\mathrm{mm}^{2} \mathrm{day}^{-2}\right)$, and 2-m temperature $\left(\mathrm{K}^{2}\right)$. Bold numbers indicate values significantly different from CTRL at a $95 \%$ confidence level based on a two-sided Student's $t$ test.

\begin{tabular}{lcccc}
\hline \hline Experiment & $\begin{array}{c}\text { Root-zone water } \\
\text { content }\end{array}$ & Evapotranspiration & Precipitation & Temperature \\
\hline CTRL & $6.4 \times 10^{-5}$ & 0.24 & 0.31 & 1.54 \\
INIT & $\mathbf{1 . 6} \times \mathbf{1 0}^{-\mathbf{4}}$ & 0.26 & $\mathbf{0 . 4 5}$ & 1.66 \\
PERT & $\mathbf{4 . 0} \times \mathbf{1 0}^{-\mathbf{4}}$ & $\mathbf{0 . 4 2}$ & $\mathbf{0 . 5 4}$ & $\mathbf{2 . 2 3}$ \\
\hline
\end{tabular}



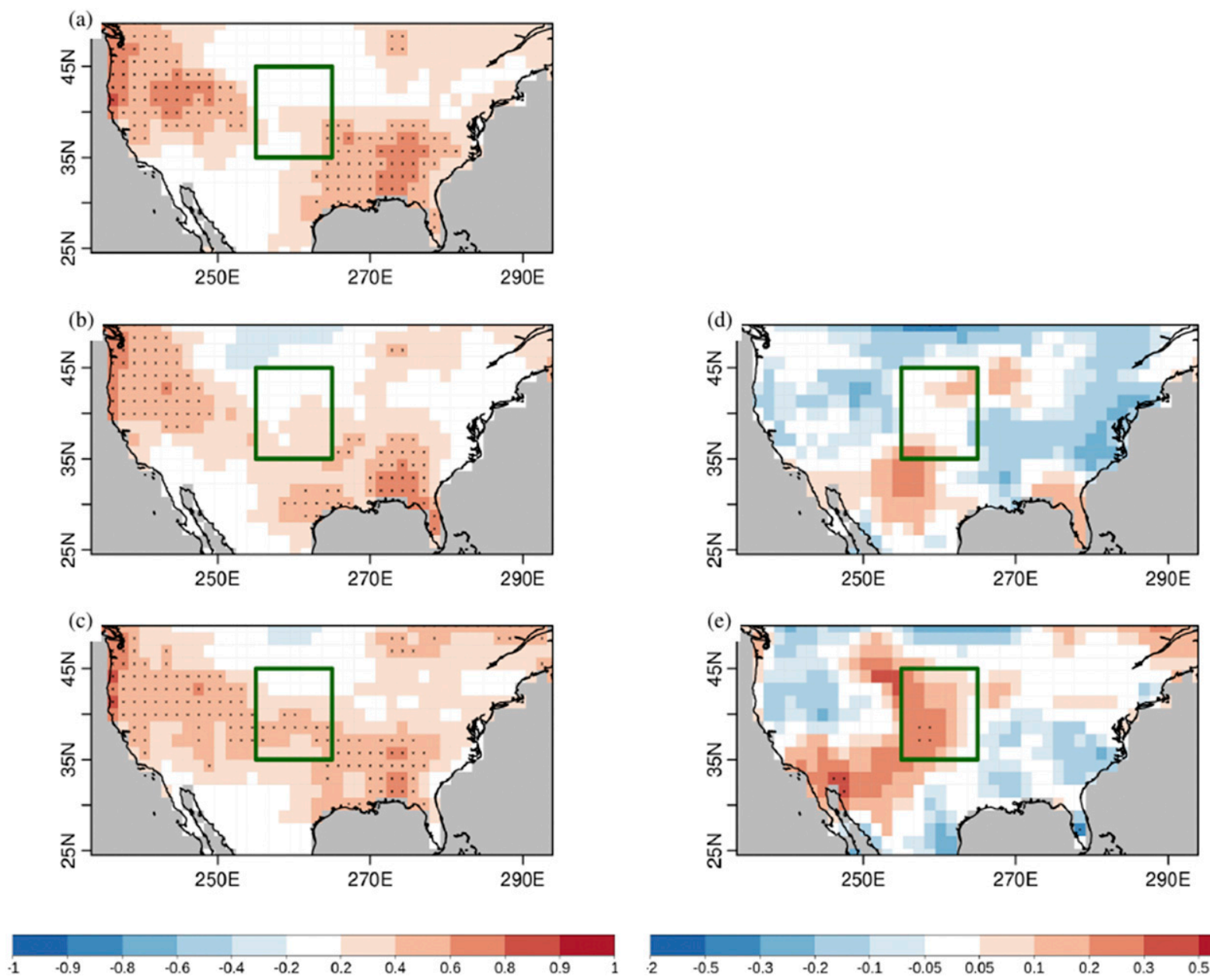

FIG. 7. (left) Temporal correlation of the mean JJA 2-m temperature over the period 1993-2014 between detrended CRU TS4 and the detrended ensemble mean of (a) CTRL, (b) INIT, and (c) PERT. (right) The correlation difference (d) INIT minus CTRL and (e) PERT minus CTRL. Stippling marks values significantly different from zero with a 95\% confidence level based on a two-sided Student's $t$ test for correlations and on the Steiger (1980) test for correlation differences.

GCMs (Lin et al. 2017), notwithstanding improved surface heat fluxes. The PERT method could therefore be a promising tool for improved temperature seasonal forecasting over the central United States, provided that it does not degrade the forecast quality elsewhere. This point is addressed in the following subsection.

\section{d. Global assessment of the methods}

The INIT and PERT methods have been applied globally. Hence, although this study mainly focuses on the U.S. Great Plains, where the model bias had been identified as an issue for seasonal forecasting, we can broaden the assessment to the rest of the globe. Figure 9 shows the summer precipitation absolute bias in the three experiments. In addition to North American central plains, the dry bias affecting many inland regions of boreal midlatitudes is alleviated with respect to CTRL, but more considerably in PERT, in particular over eastern Europe. Over central Russia, the dry bias is even turned into a wet one in PERT. However, the experiments do not reveal any striking change for wet biased regions. Soil moisture has a limited impact on the surface climate there, either because they correspond to energy-limited regimes (i.e., soil moisture is plentiful and the Bowen ratio is mainly driven by incoming surface radiation) or because the boundary layer development is little sensitive to changes in the evaporative fraction. In the Southern Hemisphere midlatitudes, the weak incoming solar radiation and the reduced share of convective precipitation characterizing the winter season prevent any significant influence of soil moisture.

Screen-level temperature bias is also greatly reduced in PERT and INIT over a vast area stretching from 


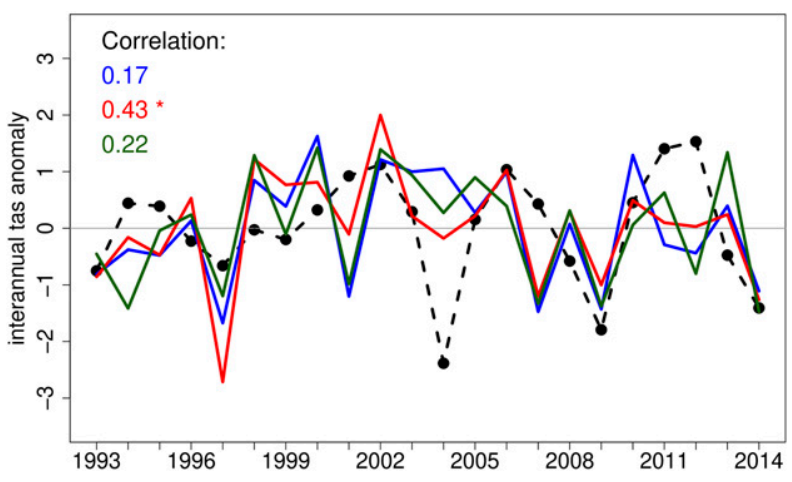

FIG. 8. Normalized yearly JJA 2-m temperature anomalies (K) over SGP for CRU TS4 (black dashed line) and the ensemble mean of CTRL (blue line), INIT (green line), and PERT (red line). The corresponding correlations with CRU TS4 are indicated in the upper-left corner of the figure, with the same color code. The asterisk marks a significant correlation with a $95 \%$ confidence level based on a two-sided Student's $t$ test.

southeastern Europe to Mongolia (Fig. 10). Here again, it should be noted that the bias reduction is more pronounced for PERT. In addition, the strong bias over Ethiopia is almost suppressed in PERT.
Despite promising results for precipitation bias mitigation, in particular over southeastern Europe, which is also a hot spot of land-atmosphere coupling, the evaluation of JJA temperature correlations does not reveal any substantial positive change in INIT and PERT with respect to CTRL (Fig. S2). This could be due to many factors. However, it should be kept in mind that unlike SGP, the dry and warm bias over Europe is not an issue shared by the majority of climate models. Hence, in our model, the causes for the dry bias in Eurasia may greatly differ from those involved in the SGP bias. We speculate that the soil moisture correction applied in this study translates very differently into temperature variability and predictability according to the region, despite a similar impact on the temperature mean state. This hypothesis is also supported by the fact that, as opposed to the homogeneous SGP region, southeastern Europe is characterized by a complex orography and soil heterogeneity, poorly resolved in our model due to a relatively coarse horizontal resolution.

As expected, the temperature correlations without any prior detrending are higher over SGP but also at

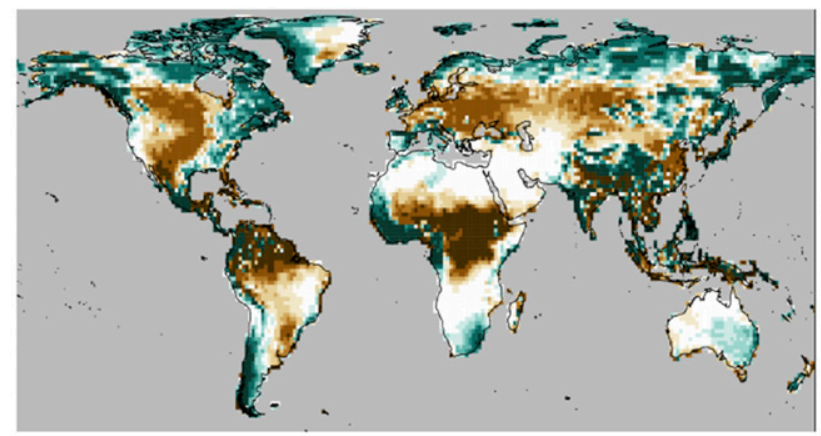

(a)

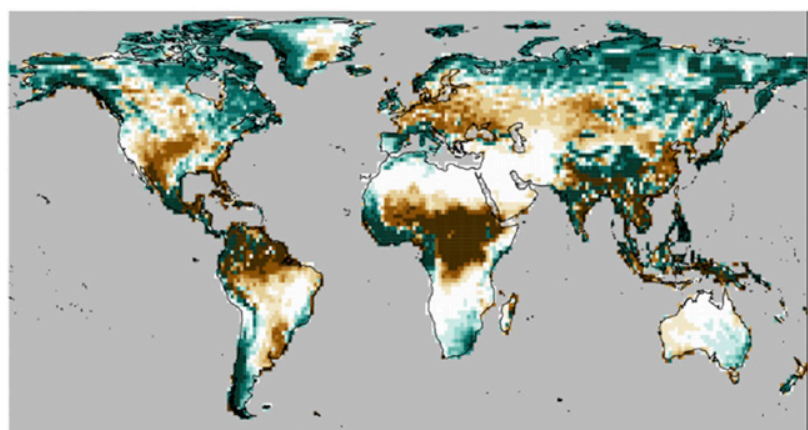

(b)

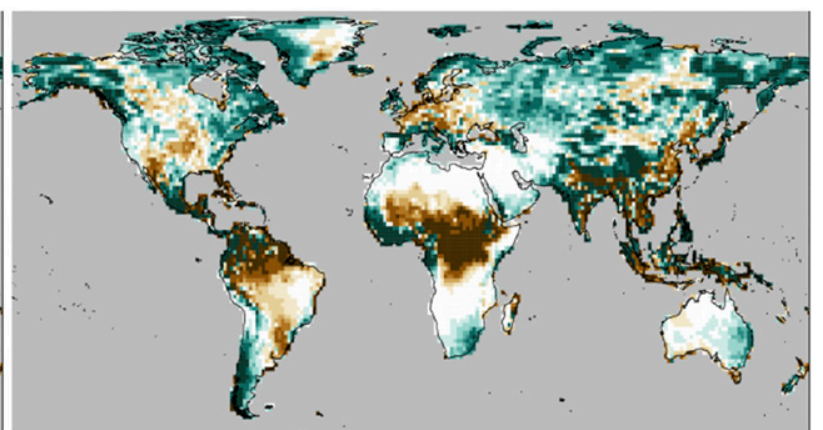

(c)

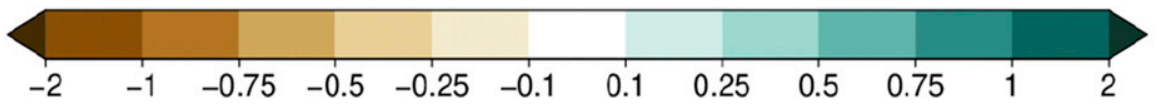

FIG. 9. As in Fig. 2, but for the global scale. 


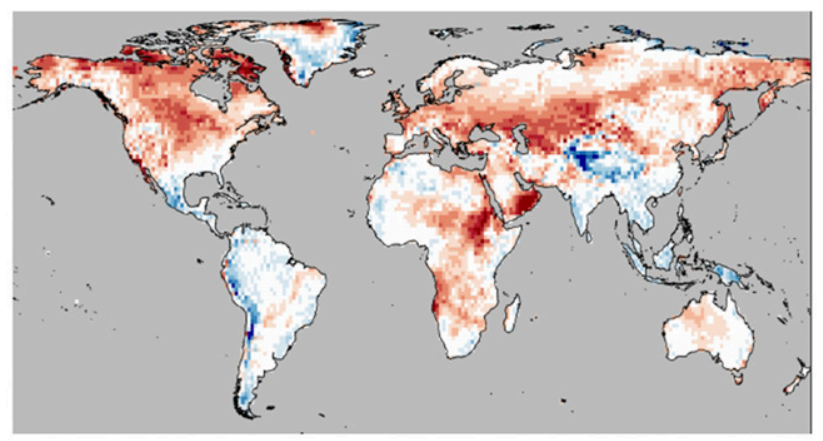

(a)

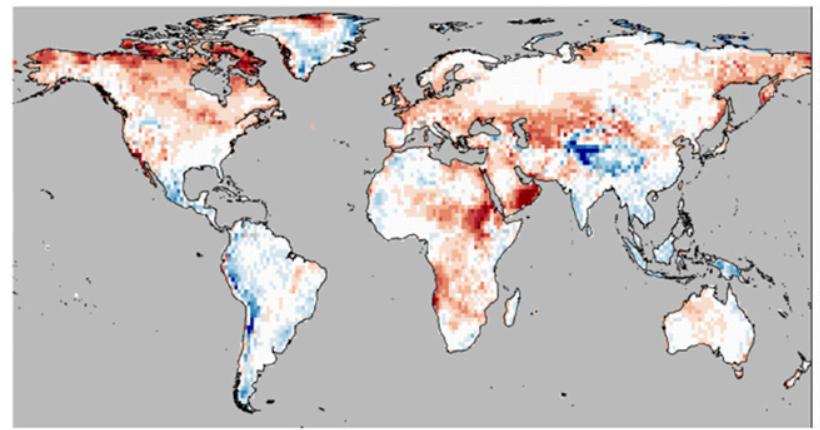

(b)

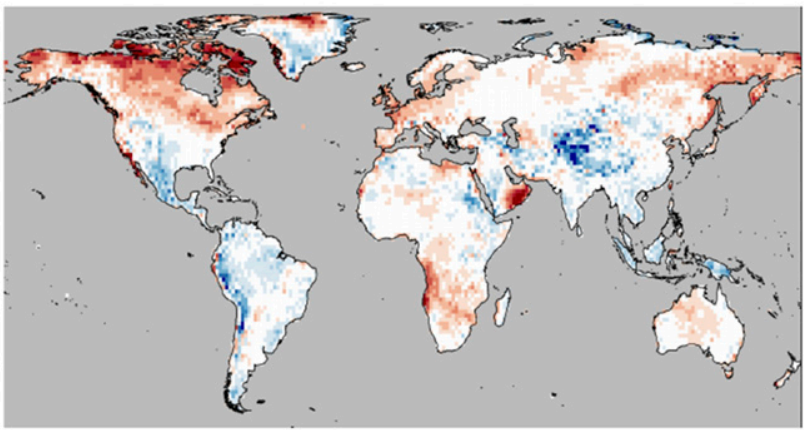

(c)

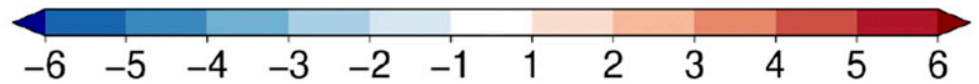

FIG. 10. As in Fig. 3, but for the global scale.

the global scale for the three experiments (Figs. S3-S5). However, leaving the trend does not reveal any major change in their comparison.

\section{Discussion}

This study investigates the relationship between climate bias and temperature prediction skill for the warm season over the U.S. Southern Great Plains, considering that soil moisture is a driver of predictability sensitive to precipitation bias. The two approaches developed here aim at counterbalancing excessive soil moisture depletion due to the precipitation bias in a dynamical seasonal forecast system, since this bias alters the imprint of soil moisture anomalies on the overlying atmosphere. The PERT method proves particularly successful. It consists in multiplying the rate of simulated precipitation feeding the land surface during the course of the forecast integration by a spatially varying factor. This factor is derived from the amplitude of the monthly relative precipitation bias of the forecast system. The "inline" PERT method indirectly corrects the soil water content, and leads to an efficient reduction of the summer precipitation and near-surface temperature biases over boreal midlatitudes, which are commonplace in climate models. Over the U.S. Southern Great Plains, this method leads to enhanced evapotranspiration and skillful summer temperature forecasts. Soil moisture and associated feedback to the atmosphere are one single piece of the puzzle explaining the climate model bias growth affecting that region, and this study does not aim to target all the processes involved in this complex issue. However, the simple correction method presented here confirms the introductory hypothesis, stating that these warm-season biases are susceptible to hamper summer predictability. Large-scale and remote interactions may also contribute to the forecast skill results found in this study, due to the GCM framework. This could be assessed in future works by reproducing the comparison CTRL/PERT setup with a regional climate model centered on the Great Plains, and with lateral boundary conditions derived from the CTRL summer reforecast. The INIT method consists in correcting the bias of soil moisture initial conditions, which is highly uncertain. Thus, it would be worth testing with other soil moisture reference datasets to evaluate the sensitivity of the reforecast skill to the initial soil moisture rescaling. At this stage, we would recommend 
to use the PERT method over INIT, not only because it leads to enhanced forecast skill, but also because it does not require any assumption on the soil moisture bias. A refinement of the PERT method, yet to be tested, would consist in gradually decreasing the corrective factor throughout the forecast integration, in order to avoid the runaway tendency leading to excessive evapotranspiration flux at the end of the summer. Finally, the current attention and efforts pursued by the climate modeling community to tackle the persisting summer bias over midlatitude continents should be monitored closely by climate forecasters since they could be a source of seasonal forecast improvement. Beyond forecasting purposes, the PERT method could also be applied to historical climate simulations in order to help identify regions for which the model precipitation and temperature biases are sensitive to the coupling between soil moisture and the atmosphere.

\section{REFERENCES}

Ardilouze, C., and Coauthors, 2017: Multi-model assessment of the impact of soil moisture initialization on mid-latitude summer predictability. Climate Dyn., 49, 3959-3974, https://doi.org/ 10.1007/s00382-017-3555-7.

Balsamo, G., and Coauthors, 2015: ERA-Interim/Land: A global land surface reanalysis data set. Hydrol. Earth Syst. Sci., 19, 389-407, https://doi.org/10.5194/hess-19-389-2015.

Beck, H. E., A. I. Van Dijk, V. Levizzani, J. Schellekens, D. Gonzalez Miralles, B. Martens, and A. De Roo, 2017: MSWEP: 3-hourly $0.25^{\circ}$ global gridded precipitation (19792015) by merging gauge, satellite, and reanalysis data. Hydrol. Earth Syst. Sci., 21, 589-615, https://doi.org/10.5194/hess-21589-2017.

Boisserie, M., B. Decharme, L. Descamps, and P. Arbogast, 2016: Land surface initialization strategy for a global reforecast dataset. Quart. J. Roy. Meteor. Soc., 142, 880-888, https:// doi.org/10.1002/qj.2688.

Brönnimann, S., 2007: Impact of El Niño-Southern Oscillation on European climate. Rev. Geophys., 45, RG3003, https://doi.org/ 10.1029/2006RG000199.

Decharme, B., and H. Douville, 2006: Uncertainties in the GSWP-2 precipitation forcing and their impacts on regional and global hydrological simulations. Climate Dyn., 27, 695-713, https:// doi.org/10.1007/s00382-006-0160-6.

— , and Coauthors, 2019: Recent changes in the ISBA-CTRIP land surface system for use in the CNRM-CM6 climate model and in global off-line hydrological applications. J. Adv. Model. Earth Syst., 11, 1207-1252, https://doi.org/ 10.1029/2018MS001545.

Dee, D. P., and Coauthors, 2011: The ERA-Interim reanalysis: Configuration and performance of the data assimilation system. Quart. J. Roy. Meteor. Soc., 137, 553-597, https://doi.org/ 10.1002/qj.828.

Dirmeyer, P. A., 2011: The terrestrial segment of soil moistureclimate coupling. Geophys. Res. Lett., 38, L16702, https:// doi.org/10.1029/2011GL048268.

Ferry, N., L. Parent, G. Garric, B. Barnier, N. C. Jourdain, and the Mercator Ocean Team, 2010: Mercator global Eddy permitting ocean reanalysis GLORYS1V1: Description and results. Mercator-Ocean Quarterly Newsletter, No. 36, Mercator Ocean International, Ramonville-Saint-Agne, France, 15-27, https://www.mercator-ocean.fr/en/science-publications/mercatorocean-journal/newsletter-36-data-assimilation-and-its-applicationto-ocean-reanalyses/.

Harris, I., and P. D. Jones, 2017: CRU TS4.01: Climatic Research Unit (CRU) Time-Series (TS) version 4.01 of highresolution gridded data of month-by-month variation in climate (Jan. 1901- Dec. 2016). Centre for Environmental Data Analysis, accessed 1 February 2019, https://doi.org/ 10.5285/58a8802721c94c66ae45c3baa4d814d0.

, — , T. J. Osborn, and D. H. Lister, 2014: Updated highresolution grids of monthly climatic observations-the CRU TS3. 10 Dataset. Int. J. Climatol., 34, 623-642, https://doi.org/ 10.1002/joc.3711.

Hewitt, C., C. Buontempo, and P. Newton, 2013: Using climate predictions to better serve society's needs. Eos, Trans. Amer. Geophys. Union, 94, 105-107, https://doi.org/10.1002/2013EO110002.

Infanti, J. M., and B. P. Kirtman, 2016: Prediction and predictability of land and atmosphere initialized CCSM4 climate forecasts over North America. J. Geophys. Res. Atmos., 121, 12 690-12 701, https://doi.org/10.1002/2016JD024932.

Kim, Y., and G. Wang, 2007: Impact of initial soil moisture anomalies on subsequent precipitation over North America in the coupled land-atmosphere model CAM3-CLM3. J. Hydrometeor., 8, 513-533, https://doi.org/10.1175/JHM611.1.

Koster, R. D., and Coauthors, 2004: Regions of strong coupling between soil moisture and precipitation. Science, 305, 11381140, https://doi.org/10.1126/science.1100217.

, and Coauthors, 2011: The second phase of the global landatmosphere coupling experiment: Soil moisture contributions to subseasonal forecast skill. J. Hydrometeor., 12, 805-822, https://doi.org/10.1175/2011JHM1365.1.

Lin, Y., W. Dong, M. Zhang, Y. Xie, W. Xue, J. Huang, and Y. Luo, 2017: Causes of model dry and warm bias over central us and impact on climate projections. Nat. Commun., 8, 881, https:// doi.org/10.1038/s41467-017-01040-2.

Martens, B., and Coauthors, 2017: GLEAM v3: Satellite-based land evaporation and root-zone soil moisture. Geosci. Model Dev., 10, 1903-1925, https://doi.org/10.5194/gmd-101903-2017.

Miralles, D., T. Holmes, R. De Jeu, J. Gash, A. Meesters, and A. Dolman, 2011: Global land-surface evaporation estimated from satellite-based observations. Hydrol. Earth Syst. Sci., 15, 453-469, https://doi.org/10.5194/hess-15-453-2011.

Mueller, B., and S. I. Seneviratne, 2012: Hot days induced by precipitation deficits at the global scale. Proc. Natl. Acad. Sci. USA, 109, 12 398-12 403, https://doi.org/10.1073/ pnas. 1204330109 .

Prodhomme, C., F. Doblas-Reyes, O. Bellprat, and E. Dutra, 2016: Impact of land-surface initialization on sub-seasonal to seasonal forecasts over Europe. Climate Dyn., 47, 919-935, https://doi.org/10.1007/s00382-015-2879-4.

Quesada, B., R. Vautard, P. Yiou, M. Hirschi, and S. I. Seneviratne, 2012: Asymmetric European summer heat predictability from wet and dry southern winters and springs. Nat. Climate Change, 2, 736, https://doi.org/10.1038/nclimate1536.

Santanello, J. A., Jr., C. D. Peters-Lidard, and S. V. Kumar, 2011: Diagnosing the sensitivity of local land-atmosphere coupling via the soil moisture-boundary layer interaction. J. Hydrometeor., 12, 766-786, https://doi.org/10.1175/JHMD-10-05014.1. 
Schneider, U., P. Finger, A. Meyer-Christoffer, E. Rustemeier, M. Ziese, and A. Becker, 2017: Evaluating the hydrological cycle over land using the newly-corrected precipitation climatology from the Global Precipitation Climatology Centre (GPCC). Atmosphere, 8, 52, https://doi.org/10.3390/ atmos 8030052 .

, A. Becker, P. Finger, A. Meyer-Christoffer, B. Rudolf, and M. Ziese, 2018: GPCC Full Data Monthly Product Version 2018 at $1.0^{\circ}$ : Monthly land-surface precipitation from raingauges built on GTS-based and historic data. DWD, accessed 1 February 2019, https://doi.org/10.5676/DWD_GPCC/FD_ M_V2018_100.

Schoetter, R., J. Cattiaux, and H. Douville, 2015: Changes of western European heat wave characteristics projected by the CMIP5 ensemble. Climate Dyn., 45, 1601-1616, https:// doi.org/10.1007/s00382-014-2434-8.
Steiger, J. H., 1980: Tests for comparing elements of a correlation matrix. Psychol. Bull., 87, 245, https://doi.org/10.1037/ 0033-2909.87.2.245.

Szczypta, C., J.-C. Calvet, C. Albergel, G. Balsamo, S. Boussetta, D. Carrer, S. Lafont, and C. Meurey, 2011: Verification of the new ECMWF ERA-Interim reanalysis over France. Hydrol. Earth Syst. Sci., 15, 647-666, https://doi.org/10.5194/hess-15647-2011.

Voldoire, A., and Coauthors, 2019: Evaluation of CMIP6 DECK experiments with CNRM-CM6-1. J. Adv. Model. Earth Syst., 11, https://doi.org/10.1029/2019MS001683.

Zhang, C., S. Xie, S. A. Klein, H.-y. Ma, S. Tang, K. Van Weverberg, C. J. Morcrette, and J. Petch, 2018: CAUSES: Diagnosis of the summertime warm bias in CMIP5 climate models at the ARM Southern Great Plains site. J. Geophys. Res. Atmos., 123, 29682992, https://doi.org/10.1002/2017JD027200. 